\title{
Predictors of Plant-Based Alternatives to Meat Consumption in Midwest University Students
}

\author{
Elizabeth D. Davitt, $\mathrm{MS}^{1}$; Donna M. Winham, $\mathrm{DrPH}^{1}$; Michelle M. Heer, BS ${ }^{1}$; \\ Mack C. Shelley, $\mathrm{PhD}^{2}$; Simon T. Knoblauch, BS ${ }^{1}$
}

\begin{abstract}
Objective: To assess the prevalence of plant-based alternatives to meat consumption in students at a Midwest university, describe associations between demographics, environmental concern attitudes, and consumption, and determine variables statistically associated with trying the plant-based alternatives.

Design: Descriptive cross-sectional convenience sample; self-administered online surveys.

Setting: College students at a Midwest university.

Participants: Currently enrolled students aged 18-30 taking courses on campus as of March 2020.

Main Outcome Measures: Plant-based alternative consumption; demographics; vegetarian status; environmental attitudes; influences on food choices; and trusted sources of food information.

Analysis: Bivariate comparisons for consumption of plant-based alternatives; logistic regression analysis.

Results: Fifty-five percent had tried a plant-based meat alternative. Top reasons were enjoying new foods and curiosity about the products. Out-of-state residency, vegetarian status, and 10 of 11 environmental attitude statements were significantly associated with plant-based alternative consumption $(P<0.05)$. About $30 \%$ of consumers indicated they wanted to eat less meat and that plant alternatives were better for the environment. Nonconsumers had less favorable views of meatless meals.

Conclusions and Implications: This study supports that positive environmental attitudes were predictive of plant-based alternative consumption among college students. Increased awareness and familiarity could encourage consumption among this population.

Key Words: college students, plant-based meat, plant protein, environmental attitudes, young adults (J Nutr Educ Behav. 2021;53:564-572.)
\end{abstract}

Accepted April 18, 2021.

For several decades, there has been a steady growth in consumer concerns about the environmental sustainability of the global food supply, animal welfare ethics, and human health consequences of red meat intakes. ${ }^{1,2}$ Consumer willingness to try new and novel food products and acceptance for plant-based foods have bolstered the market expansion in many industry sectors. ${ }^{3}$ The retail sales of plant-

\section{INTRODUCTION}

based alternatives to meat in the US increased by 38\% between 2017 and 2019. ${ }^{4}$ Although plant-based alternatives to meat make up only $3 \%$ of total retail meat purchases, the market growth potential is high, and consumer demand is expected to continue. ${ }^{4}$

The 2015-2020 Dietary Guidelines for Americans recommended reduced meat intake to lower the risk of cardiovascular disease. ${ }^{5}$ In 2015 , the International Agency for Research on

\footnotetext{
${ }^{1}$ Food Science and Human Nutrition, College of Human Sciences, Iowa State University, Ames, IA

${ }^{2}$ Departments of Political Science and Statistics, College of Liberal Arts and Sciences, Iowa State University, Ames, IA

Conflict of Interest Disclosure: The authors have not stated any conflicts of interest.

Address for correspondence: Donna M. Winham, DrPH, Food Science and Human Nutrition, College of Agriculture and Life Sciences, Iowa State University, 2302 Osborn Dr, Ames, IA 50011-1078; E-mail: dwinham@iastate.edu

(C) 2021 The Authors. Published by Elsevier Inc. on behalf of Society for Nutrition Education and Behavior. This is an open access article under the CC BY-NC-ND license (http:// creativecommons.org/licenses/by-nc-nd/4.0/)

https://doi.org/10.1016/j.jneb.2021.04.459
}

Cancer classified processed meats as carcinogenic and suggested that red meats likely were too, based on epidemiological associations between their consumption and intestinal cancers. ${ }^{6}$ By 2019, the EAT-Lancet Commission on Food, Planet, Health highlighted the links between healthy diets, sustainable agriculture, and environmental degradation. ${ }^{7}$ The EAT report explicitly calls for increased plant protein sources and lower red meat consumption to manifest transformation in the global food system for environmental concerns, human health, and food security. ${ }^{\text {? }}$

Plant-based foods, including a variety of plant-based alternatives to meat, such as Beyond Meat or Impossible Burger, can deliver environmental and sustainability advantages over animalbased products. ${ }^{1,7,8}$ A complete life cycle assessment of plant-based burger production indicated over $90 \%$ reduction in greenhouse gas emissions, water use, and land impact. ${ }^{8}$ Production of a Beyond Meat burger required 
46\% less energy than an equivalentsized quarter-pound of US beef. ${ }^{8}$

Values, beliefs, and norms are motivators for adopting plant-based diets and are reflected in the degree and type of dietary pattern implementation. Vegetarians and vegans are driven by ethical reasons, whereas semivegetarians or flexitarians seem more inspired by health or fitness concerns. ${ }^{9}$ While studies like the EAT-Lancet 2019 report emphasize environmental and planetary issues, those who choose plant-based diets for these reasons may be a small minority. ${ }^{7,10}$ Ecology-oriented meatreducers and vegetarians/vegans are typically young, urban, more liberal, and have a higher proportion of female adherents. ${ }^{9}$ An additional belief factor in food choice is the degree of consumer trust in stakeholders, for example, health professionals, scientists, media, and food companies. ${ }^{11}$ Core cultural and normative factors such as taste, familiarity, cost, and convenience also influence food selection behaviors. ${ }^{12}$

Even though market demand has risen for plant-based alternatives to meat, particularly among young adults or college students, few studies beyond economic price comparisons have examined consumer motivations or influences on these food choices. ${ }^{1,10}$ As emerging adults, college students are exploring their food environments and developing dietary patterns to last a lifetime. ${ }^{13,14}$ One study suggests that about $6.2 \%$ of college students are vegetarians. ${ }^{15}$ In younger adolescents, this dietary pattern correlates with more healthful intakes than is true for nonvegetarians. ${ }^{16}$ In turn, reductions in meat consumption have been associated with higher fruit and vegetable intakes. ${ }^{17}$ However, the prevalence of plant-based alternatives to meat consumption among college students and their reasons for choosing these products is unclear. ${ }^{9,16,18}$

Understanding associations with environmental attitudes and motivators for choosing plant-based alternatives to meat can assist in promotion efforts when young adults are amenable to diet change. ${ }^{14,18}$ Identification of the trusted sources of nutrition, health, and food messaging by university students is essential to understand what sources influence food behaviors. ${ }^{12}$ In some situations, increasing the availability of choices to include environmentally friendly options can facilitate the promotion of such options on campuses. ${ }^{18}$

Drawing on constructs from the Value-Belief-Norm theory (values, responsibility, self-beliefs, and personal norms) to study proenvironmental food behavior, ${ }^{19-21}$ and views toward vegetarianism, ${ }^{22}$ the pilot study objectives were to (1) assess the prevalence of plant-based alternatives to meat consumption among Iowa State University students, (2) describe associations between demographics, attitudes toward environmental concerns, and consumption, and (3) determine variables that are statistically associated with trying plant-based meat alternatives. It was hypothesized that there would be a positive relationship between concern for the environment and trying plant-based alternatives to meat among university students.

\section{METHODS}

\section{Study Design and Participants}

The cross-sectional study surveyed enrolled students aged 18-30 years who were physically attending classes at Iowa State University as of March 2020. The overarching project collected information on food security, food practices, and pulse consumption (beans, peas, lentils, chickpeas, etc) as a function of the COVID-19 pandemic. Data on pulse preferences and consumption patterns are presented elsewhere. ${ }^{23}$ Research questions on plant-based alternatives to meat are reported here.

With the Registrar's office permission, a direct email invitation was sent to 29,810 student university email addresses between April 26-30, 2020, using Survey Monkey software (San Mateo, CA). Email addresses from students under 18 years, those with no-release requests, and the professional students at the College of Veterinary Medicine were excluded. Of the total emails sent, 12,958 were not opened; 19,152 were at least clicked open; and 1,907 survey responses were given. The response rate was $\sim 10 \%(1,907$ of 19,152$)$. The email subject line focused on food, shopping, and diet influences after the COVID-related physical closedown of campus. Respondents spent an average of 17 minutes on the survey, and completion was considered informed consent. The 67-question instrument had 14 items requiring a response to continue, of which 6 questions determined eligibility to continue in the survey, and an additional 6 yes/no items governed skip patterns. Two questions were integrity checks for seriousness of responses (self-reported level of honesty in response, degree of accuracy in answers). ${ }^{24}$ All other questions were optional. The survey was pilot-tested with 17 university students, and 5 faculty members in nutritional sciences reviewed the survey content. Following pilot and reviews, question order and wording were adjusted for some items. Respondents who met eligibility criteria received a $\$ 5$ e-gift card to Amazon.com after surveys were checked for at least $75 \%$ completion. The Iowa State University Institutional Review Board approved the study protocol.

\section{Survey Development}

Demographic questions for age, gender (male, female, transgender/nonbinary, prefer not to answer), Hispanic ethnicity, race, residency classification (in-state, out-of-state, international), and fruit and vegetable servings per day were adopted from the 2018 American College Health Association survey. $^{25}$ Respondents self-reported their university college and if they were vegetarian or vegan (M.B. Hiller, unpublished data, July 2019).

Following the Values-BeliefsNorms theory, ${ }^{19-21}$ and the work of Erinosho et $\mathrm{al}^{22}$ on food attitudes and behaviors, 11 Likert-type statements assessed environmental values, beliefs, knowledge, spirituality, and views about vegetarianism using a 5point range. Four items were adapted from the Food Attitudes and Behaviors Survey, ${ }^{22} 1$ from the New Ecological Paradigm survey, ${ }^{26}$ and 6 from the IFIC consumer survey on plant-based alternatives to meat. $^{27}$

Respondents rank-ordered ( $1=$ most influence; 7 = least influence) 7 factors which influenced their decisions to 
buy specific foods (taste, price, healthfulness, familiarity, convenience, nutrition, and environmental sustainability). ${ }^{28}$ Using a 5-point Likert structure (extremely trust, very much trust, moderately trust, slightly trust, not at all trust), students indicated which people or sources they trusted to provide accurate information about foods to eat or to avoid. ${ }^{29}$ The 10 options were registered dietitians, health care professionals, health coaches, fitness professionals, healthfocused websites, scientific studies, chefs or culinary professionals, friends or family, health and nutrition bloggers, and food companies. ${ }^{29}$

Respondents were asked if they had ever eaten a food product that was a plant alternative to animal meat, modeled verbatim from the 2020 IFIC survey. ${ }^{27}$ The term meat was not defined further, but an explanation of "one made to resemble meat like the Impossible Burger" was provided. Respondents who answered yes could select multiple options from 13 choices and/or write-in an explanation as to why they tried the meat alternative. ${ }^{27}$

\section{Data Transformations and Analysis}

Survey data were analyzed using SPSS (version 26.0, IBM, Armonk, NY, 2019). Data were examined for normality of frequency distributions. Likert responses for attitude statements were condensed from 5 categories (strongly disagree, disagree, neutral, agree, strongly agree) to 3 (disagree, neutral, and agree) for analysis. Bivariate comparisons for plant-based alternatives to meat (not eaten/has eaten) were made using Pearson chi-square for independence between demographic and attitudinal variables. Variables significant by consumption status or theoretically important, for example, gender, ${ }^{9}$ were entered into logistic regression analysis. The most parsimonious number of variables was derived using the forward conditional selection procedure to evaluate which variables were significant contributors to correct classification of student consumption responses using logistic regression.

\section{RESULTS}

Of the 1,907 students who started the survey, 1,434 (75\%) provided complete data for the variables of interest (mean age $21.4 \pm 2.7$ years; 61\% female, $82 \%$ White, 56\% from Iowa). In comparison, Spring 2020 university enrollment data indicate the overall student population was $43 \%$ female, $85 \%$ White, and $60 \%$ instate. ${ }^{30}$ Excluded were 161 ineligible students, 37 with implausible answers, and 268 with incomplete variables of interest for this analysis. There were no statistically significant gender, age, or university college differences by survey completion status.

Fifty-five percent had consumed a plant-based alternative to meat. A significantly greater portion of outof-state students, those with higher fruit and vegetable intakes, and vegetarians or vegans had eaten plantbased alternatives. Students in the College of Agriculture and Life Sciences were significantly less likely than those from other colleges to have tried these foods (Table 1).

Reasons for eating a plant-based alternative to animal meat are shown in Table 2. Respondents could select multiple options for why they chose to try a plant-based alternative to meat. Two-thirds stated that they liked to try new foods, and over half indicated curiosity about the food products. Taste and encouragement of friends or family were drivers for approximately $40 \%$ of consumers. About 30\% indicated that they were trying to eat less meat and that plant alternatives were better for the environment. Only 20\%-25\% specified health, animal welfare, or cost as reasons. National survey data are also shown in Table 2 and presented in the Discussion. ${ }^{27}$

Attitudes toward environmental sustainability, spirituality, vegetarianism, and environmental and nutrition awareness are shown in Table 3. Significantly higher percentages of those who had tried plant-based alternatives agreed that these foods are better for the environment, provide adequate protein, nature's balance is delicate, and knew metal packaging is easier to recycle than plastic compared to those who had not eaten these food products. Plant-alternative consumers disagreed with statements that environmentally sustainable food production was unimportant, dinner does not seem right without meat, vegetarians are "different," and food does not affect health. ${ }^{22}$ More nonplant-alternative consumers considered themselves spiritual than did consumers. There was no difference between groups for agreement that an environmentally sustainable diet can include protein from animal and plant sources. However, plant-alternative consumers disagreed more than nonconsumers with the factual statement that meat is the most complete protein (Table 3$)$.

The mean ( \pm SD) Likert scores rankings for the 7 influences on food purchase decisions $(1=$ most influence; $7=$ least influence) were in the priority order of taste $(2.9 \pm 1.8)$, price or cost $(3.1 \pm 1.8)$, nutrition $(3.5 \pm 1.7)$, healthfulness $(4.1 \pm 1.7)$, familiarity $(4.2 \pm 1.9)$, convenience $(4.4 \pm 1.7)$, and environmental sustainability $(5.9 \pm 1.6)$. Those who had tried the plant alternatives ranked environmental sustainability (5.8 vs 6.0), healthfulness (3.9 vs 4.2 ), and nutrition (3.3 vs 3.7 ) more favorably as influences on general food choices than their peers ( $P$ $<0.001$ for all). The nonconsumers viewed convenience ( 4.2 vs $4.5, P$ $<0.001$ ) and familiarity (3.9 vs $4.3, P$ $<0.001$ ) as more influential on their food choices than did the plant alternative consumers.

The mean $( \pm S D)$ trust rankings of 10 information sources about foods from high trust (1) to low trust (5) were: registered dietitians $(1.6 \pm 0.8)$, medical professionals $(1.8 \pm 0.8)$, scientific studies (2.1 \pm 0.9$)$, health coaches $(2.3 \pm 0.9)$, personal trainers $(2.5 \pm 0.9)$, culinary professionals $(2.6$ $\pm 0.9)$, health website $(3.1 \pm 0.9)$, friends and family (3.2 \pm 0.9$)$, health and nutrition bloggers (3.5 \pm 0.9$)$, and food companies (3.8 \pm 0.9$)$. Plant alternative consumers had significantly higher perceived trust for scientific studies (2.0 vs 2.2; $P=0.003$ ) and greater distrust of health bloggers (3.6 vs $3.4 ; P=0.014$ ) than nonconsumers. Significantly higher trust rankings for friends and family (3.1 vs 3.3; $P=0.001$ ), food companies ( $3.7 \mathrm{vs}$ $3.9 ; P=0.001)$, and personal trainers (2.5 vs $2.6 ; P=0.020$ ) were held by 


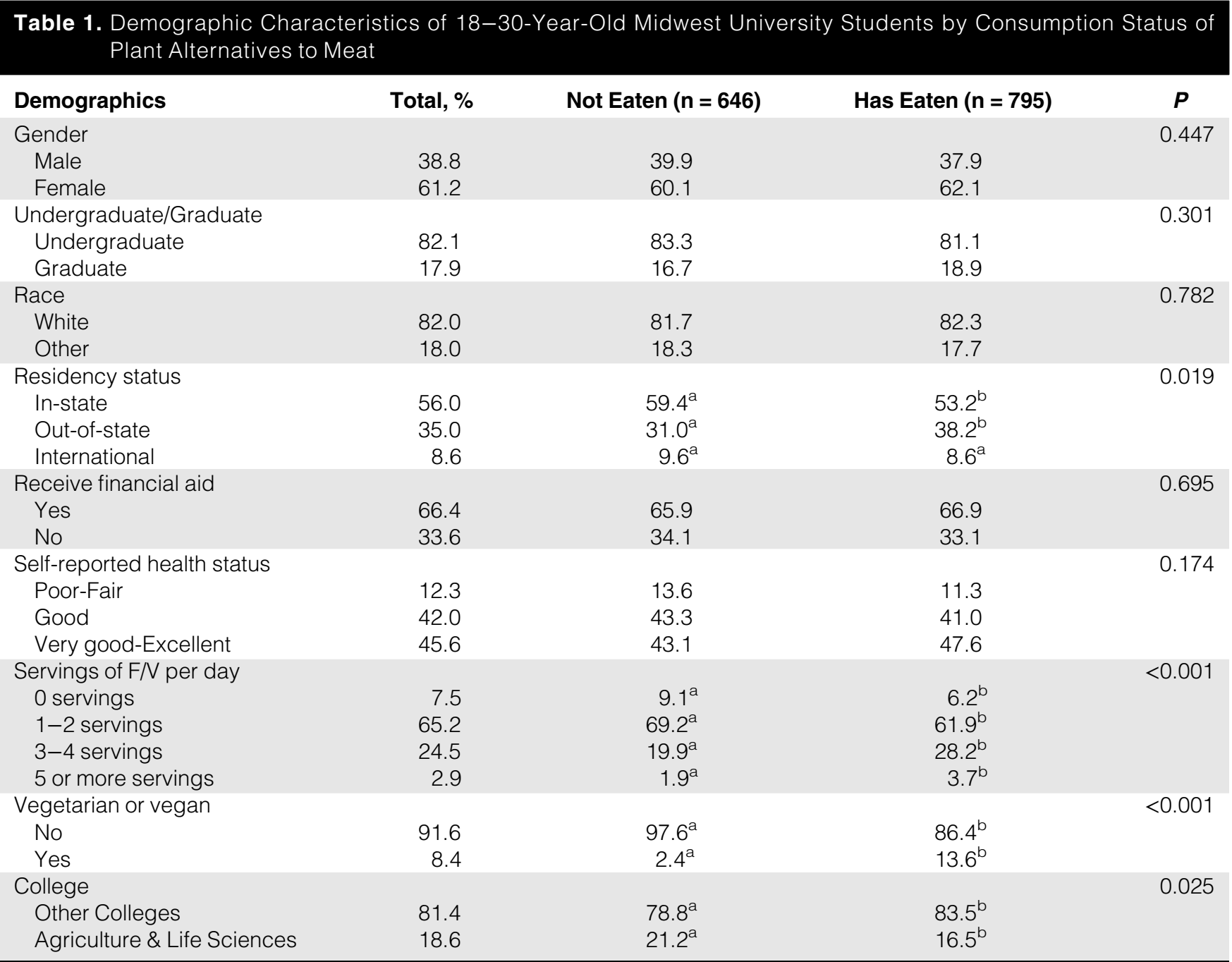

F/V indicates fruits and vegetables.

Note: Values of $P<0.05$ considered statistically significant. Different superscript letters ( $a$ and $b)$ signify column proportions that are significantly different from each other by chi-square test of independence analysis.

nonconsumers than their plant alternative consuming peers.

A logistic regression model was estimated to ascertain whether the independent variables of age, gender, vegetarian status, fruit and vegetable intakes, out-of-state residency status, rank-order value of 5 of 7 food choice drivers, level of trust for 5 of 10 sources of food information, and the 11 attitude statements were statistically associated with the dependent variable of plant-based alternatives to meat consumption. Table 4 shows the most parsimonious significant model $(P<0.001)$, which included 10 variables (out-of-state residency, vegetarian/vegan status, rank-order of nutrition influence on food choice, degree of trust for health bloggers, and 6 attitude statements). The model correctly classified $68.3 \%$ of reported plant alternatives to meat consumption, including $60.0 \%$ of instances for nonconsumption (specificity) and $75.0 \%$ instances of consumption (sensitivity) of this food type (model $P<0.001$ ). Logistic regression fit metrics indicate that the model performs adequately (Cox and Snell pseudo- $R^{2}=0.186$ and $\mathrm{Na}$ gelkerke pseudo- $\left.R^{2}=0.249\right)$.

\section{DISCUSSION}

The first objective of this pilot study was to assess the prevalence of trying plant-based alternatives to meat and the reasons for doing so among Midwest university students. About 55\% had eaten plant-based alternatives to meat, similar to that found from a recent national IFIC survey where $50 \%$ of US consumers aged 18-80 had tried these foods. ${ }^{27}$ Nationally, gender differences were observed, with $53 \%$ of men and $44 \%$ of women reporting consumption of meat alternatives. ${ }^{27}$ Van Loo et $\mathrm{al}^{1}$ found stronger preferences for plant-based and lab-grown meat over farm-raised beef among vegetarians, males, younger, and more highly educated individuals in another national survey. There were no gender differences among the Midwest university students in plantbased alternatives consumption.

When asked why they tried plantbased alternatives, Midwest university students and the IFIC national 
Table 2. Reasons for Choosing to Consume a Plant Alternative to Meat Among Midwest University Students Aged 18 -30 years in Comparison to National Consumers Aged 18-80 Years

\begin{tabular}{|c|c|c|c|c|c|c|}
\hline $\begin{array}{l}\text { Why Did You Decide to Eat a } \\
\text { Plant Alternative to Meat? }\end{array}$ & $\begin{array}{c}\text { Midwest } \\
\text { University } \\
\text { (n= 795), } \\
\%\end{array}$ & $\begin{array}{c}\text { National } \\
\text { Sample }^{a} \\
(\mathrm{n}=485) \\
\%\end{array}$ & $\begin{array}{l}\text { Chi- } \\
\text { Square }\end{array}$ & $\begin{array}{c}\% \\
\text { Difference }\end{array}$ & $\begin{array}{l}\text { Confidence } \\
\text { Interval for } \\
\% \text { Difference }\end{array}$ & $\boldsymbol{P}$ \\
\hline I like to try new foods & 66.4 & 41 & 79.129 & 25.4 & $19.84,30.75$ & $<0.0001$ \\
\hline Heard a lot about them and was curious & 54.1 & 30 & 70.644 & 24.1 & $18.63,29.30$ & $<0.0001$ \\
\hline Thought it would taste good & 40.3 & 26 & 27.098 & 14.3 & $9.02,19.36$ & $<0.0001$ \\
\hline Encouraged to try by friends or family & 38.2 & 20 & 46.363 & 18.2 & $13.17,22.97$ & $<0.0001$ \\
\hline $\begin{array}{l}\text { Believe plant alternatives are better } \\
\text { for the environment }\end{array}$ & 30.8 & 27 & 2.096 & 3.8 & $-1.36,8.80$ & 0.1477 \\
\hline Ingredients intrigued me & 29.9 & 23 & 7.223 & 6.9 & $1.89,11.71$ & 0.0072 \\
\hline Trying to eat less meat & 29.8 & 27 & 1.152 & 2.8 & $-2.34,7.78$ & 0.2831 \\
\hline $\begin{array}{l}\text { Believe plant alternatives are } \\
\text { better for health }\end{array}$ & 25.7 & 24 & 0.463 & 1.7 & $-3.25,6.47$ & 0.4961 \\
\hline On a menu of a restaurant I like & 21.8 & 17 & 4.337 & 4.8 & $0.28,9.10$ & 0.0373 \\
\hline Made without harming animals & 20.8 & 26 & 4.628 & -5.2 & $0.46,10.08$ & 0.0315 \\
\hline Reasonably priced & 19.1 & 23 & 2.8 & -3.9 & $-0.65,8.62$ & 0.0942 \\
\hline No specific reason & 9.7 & 2 & 28.227 & 7.7 & $5.19,10.14$ & $<0.0001$ \\
\hline Noticed in the meat aisle of the store & 7.3 & 12 & 8.053 & -4.7 & $1.41,8.28$ & 0.0045 \\
\hline
\end{tabular}

${ }^{a}$ Question responses and data from International Food Information Council Foundation. A Consumer Survey on Plant Alternatives to Animal Meat. ${ }^{27}$

Note: Could select multiple responses. Values of $P<0.05$ considered statistically significant. Chi-square test of independence was conducted.

sample had similar reasons but a different frequency of mentions. Liking to try new foods and curiosity about these foods were given as frequent reasons by both. ${ }^{27}$ The IFIC respondents expressed more support for environmental reasons in their choice to eat the alternative foods than did the Midwest university students, who more frequently indicated taste and social factors, for example, encouraged by friends or family, over environmental reasons. ${ }^{27}$

A second study objective was to determine which variables related significantly to trying plant-based alternatives. This analysis supports the influence of environmental values, beliefs, and norms for trying plantbased alternatives to meat among students. The logistic regression model provided a rigorous examination of the variables that are significantly associated with consumption patterns. The results provide datadriven evidence of the influences underlying consumption of plant alternatives to meat, thereby establishing a strong foundation for both policy and practice recommendations. Attitudes toward environmental issues and vegetarianism, less trust in nutrition bloggers as a source of information, the influence of nutrition on purchase decisions, and out-of-state student status were associated with consumption of plant alternatives to meat. Vegetarians showing a stronger preference for plant-based alternatives than animal-based meats is expected. ${ }^{1,31}$ In another study, about $50 \%$ of vegans stated they practice eating habits to aid in environmental protection. ${ }^{32}$ The out-of-state student status association with plant alternative consumption is unexplained. Some speculations are that out-of-state students may have more financial resources, exposure to new foods, or willingness to experiment with tastes than more rural in-state students. In-state students may also be reluctant to try plant alternatives given a strong local agricultural livestock tradition. Unlike the significant differences in plant-alternative consumption by student residency status, the region of residence did not significantly affect beef or beef-alternative selection in the national survey by Van Loo et al. ${ }^{1}$

Views negatively associated with having eaten plant-based alternatives to meat included agreement that dinner did not seem right without meat, that vegetarians are a bit different, and disagreement that the balance of nature is very delicate and easily upset. While gender, college, or residency status were not associated with the previous attitude statements, there may be stigma toward vegetarianism or a priority emphasis on meat. Iowa State University is noted for its agriculture degree programs, and Iowa is a top producer of hogs and chickens, and grower of livestock feed. ${ }^{33}$ In an Iowa study of low-income women's food choices, meat was viewed as an essential part of meals for adequate nutrition. There was reluctance to move away from meat consumption. ${ }^{34}$ In an Australian study, committed meat eaters were less likely to believe livestock farming contributes to climate change and more likely to perceive meat-free diets as inadequate and inconvenient compared to those who were willing to reduce their meat consumption. ${ }^{35}$

Although information was shown to have a small impact on consumer choice in the national survey by Van Loo et al, the largest effect on increasing consumer preference for plantbased meats was in providing facts on environmental and animal welfare benefits. ${ }^{1}$ Opinion research with 
Table 3. Attitudes About Environmental Issues, Vegetarianism, and Environmental and Nutrition Awareness Among Midwest University Students Aged 18-30 Years by Consumption of Plant Alternatives to Meat

\section{Attitude Statements}

Attitudes toward environmental issues

Not important to me if foods are produced in

an environmentally sustainable way

Disagree
Neither
Agree

Plant alternative meats are better for the environment

\section{Disagree}

Neither

Agree

The balance of nature is very delicate and easily upset

Disagree

Neither

Agree

I consider myself to be a spiritual person

Disagree

Neither

Agree

Attitudes toward meat and vegetarianism

Dinner does not seem right without meat

\section{Disagree}

Neither

Agree

Vegetarians are a bit different

Disagree

Neither

Agree

Environmental and nutrition awareness

An environmentally sustainable diet can include

protein from animal and plant sources

\section{Disagree}

Neither

Agree

Plant-based foods can provide all the protein I need

\section{Disagree}

Neither

Agree

Aluminum and tin packaging are easier

to recycle than plastic packaging

\section{Disagree}

Neither

Agree

What I eat does not really affect my health

Disagree

Neither

Agree

Meat is the most complete source of protein

Disagree

Neither

Agree
Total

Not Eaten $(n=646)$
Has Eaten $(n=795)$
$\boldsymbol{P}$

$<0.001$

48.8

31.1

20.1

$40.9^{a}$

$36.4^{\mathrm{a}}$

$22.8^{\mathrm{a}}$

25.7

36.3

37.9

$37.1^{\mathrm{a}}$

$39.4^{a}$

$23.6^{\mathrm{a}}$

17.4

36.5

$17.4^{\mathrm{a}}$

$41.4^{a}$

$41.2^{\mathrm{a}}$

46.1

34.0

20.7

45.3

$30.0^{a}$

$20.5^{\mathrm{a}}$

$49.5^{a}$

35.4

17.5

47.0

50.5

25.8

23.8

$22.0^{\mathrm{a}}$

$18.1^{a}$

$59.8^{a}$

$39.2^{a}$

$29.9^{a}$

$30.9^{a}$

0.196

7.6

14.0

6.3

15.0

78.6

8.6

13.1

78.5

$57.4^{\mathrm{a}}$

$22.0^{\mathrm{a}}$

$20.6^{a}$

78.5

42.8

20.6

36.6

$<0.001$

$17.0^{\mathrm{a}}$

$36.6^{\mathrm{b}}$

$59.6^{b}$

$22.4^{\mathrm{b}}$

$18.0^{\mathrm{b}}$

$<0.001$

0.001

0.006

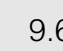

46.1

$10.1^{\mathrm{a}}$

$49.8^{a}$

$40.2^{\mathrm{a}}$

93.0

4.1

$91.0^{\mathrm{a}}$

$5.7^{\mathrm{a}}$

$3.3^{\mathrm{a}}$

23.4

23.9

52.7 $13.9^{a}$

$21.4^{\mathrm{a}}$

$64.7^{a}$ $30.9^{\mathrm{b}}$

$19.4^{\mathrm{a}}$

$49.6^{b}$

0.013

$<0.001$

$<0.001$

0.015

$9.2^{\mathrm{a}}$

$43.1^{\mathrm{b}}$

$47.7^{\mathrm{b}}$

$94.6^{\mathrm{b}}$

$2.8^{\mathrm{b}}$

$2.6^{a}$

$31.1^{\mathrm{b}}$

$25.9^{\mathrm{b}}$

$42.9^{b}$

Note: Values are percentages. Values of $P<0.05$ are considered statistically significant. Different superscript letters (a and b) signify column proportions that are significantly different from each other by chi-square test of independence analysis. 
Table 4. Logistic Regression Model of Predictors of Plant Alternative to Meat Consumption of Midwest University Students Aged 18-30 Years

\begin{tabular}{|c|c|c|c|c|c|}
\hline \multirow[b]{2}{*}{ Demographics } & \multirow[b]{2}{*}{ B (SE) } & \multirow[b]{2}{*}{$\boldsymbol{P}$} & \multicolumn{3}{|c|}{$\begin{array}{l}95 \% \text { Confidence Interval } \\
\text { for Odds Ratio }\end{array}$} \\
\hline & & & Lower & Odds Ratio & Upper \\
\hline Out-of-state residency & $0.306(0.127)$ & 0.016 & 1.059 & 1.358 & 1.743 \\
\hline Vegetarian or vegan (1) & $0.729(0.318)$ & 0.022 & 1.112 & 2.073 & 3.865 \\
\hline Nutrition influence rank & $-0.113(0.035)$ & 0.001 & 0.835 & 0.893 & 0.956 \\
\hline Health-nutrition bloggers trust rank & $0.912(0.065)$ & 0.003 & 1.067 & 1.212 & 1.377 \\
\hline \multicolumn{6}{|l|}{ Attitudes } \\
\hline Plant alternatives to meat better for the environment & $0.433(0.067)$ & $<0.001$ & 1.352 & 1.541 & 1.757 \\
\hline Plant-based foods can provide all the protein I need & $0.284(0.061)$ & $<0.001$ & 1.178 & 1.328 & 1.497 \\
\hline Dinner does not seem right without meat & $-0.200(0.75)$ & $<0.001$ & 0.734 & 0.818 & 0.913 \\
\hline $\begin{array}{l}\text { An environmentally sustainable diet can } \\
\text { include animal \& plant protein }\end{array}$ & $0.241(0.075)$ & 0.001 & 1.098 & 1.273 & 1.476 \\
\hline Vegetarians are a bit different & $-1.48(0.062)$ & 0.016 & 0.764 & 0.862 & 0.973 \\
\hline $\begin{array}{l}\text { The balance of nature is very } \\
\text { delicate and easily upset }\end{array}$ & $-0.139(0.067)$ & 0.038 & 0.763 & 0.870 & 0.992 \\
\hline Constant & $-1.833(0.574)$ & 0.001 & & 0.160 & \\
\hline \multirow[t]{2}{*}{ Percent correct } & \multicolumn{2}{|c|}{$\begin{array}{l}\text { Has NOT eaten plant } \\
\text { alternatives } \\
\text { (specificity) }\end{array}$} & 60.0 & Overall & 68.3 \\
\hline & \multicolumn{2}{|c|}{$\begin{array}{l}\text { Has eaten plant } \\
\text { alternatives (sensitivity) }\end{array}$} & 75.0 & Cut-point $=0.5$ & \\
\hline
\end{tabular}

other college students has shown that exposure to climate change science leads to stronger beliefs and support for climate-protective actions. ${ }^{21}$ Similarly, education on environmental issues can lead individuals to take action to change. ${ }^{18,21}$ In addition, institutions can implement plant-based alternatives into daily menus to decrease their carbon footprint, model environmental behaviors, and save money. ${ }^{36}$

The study has several strengths and limitations. The demographic characteristics of the relatively large sample approximated those of the university and the Midwest overall. However, as a convenience sample from 1 university, the generalizability of the findings is limited. The definition for meat was not provided, and only a brief explanation of plant alternatives to animal meat was given. Nonconsumers were not asked why they had not tried plant-based alternatives to meat. Therefore, nonconsumer barriers and priorities to plant alternative consumption were not assessed. The specific types of plant-based meats, consumption frequencies, and amounts were not reported. Although survey subject lines focused on food consumption in general, it is possible respondents were biased toward the topics of inquiry. The university is located in an agricultural state with a strong tradition of meat production, which likely influenced students' opinions on topics including meat consumption, plant alternatives, and vegetarianism/veganism. The attitude statements are purposely subjective and may therefore be more open to interpretation (listed in Table 3).

\section{IMPLICATIONS FOR RESEARCH AND PRACTICE}

This study supports the conclusion that those Midwest university students who had positive environmental attitudes were more likely to consume plant-based alternatives to meat. Gender may not be as influential in this age group as in other populations. Nutrition may be a greater driver of food choice decisions for plant-based alternatives for some college students. Messaging from trusted health professionals and media may encourage consumption as well as underlying values, beliefs, and norms toward environmental sustainability. Additional research may determine to what extent these views are informed by factors such as geographic region. These data support future studies to focus on providing education on environmental and animal welfare issues to increase plant-based alternative consumption. Future research may investigate how to further incentivize their consumption and parlay interest in these products' novelty into knowledge of their environmental and health benefits.

Furthermore, these data support trust in health care figures. Registered dietitians and other qualified medical professionals may be effective messengers for this information as awareness of plant-based alternatives to meat continues to grow. Interventions will need to be cognizant of the differences among prospective consumers, recognizing the range of influences in food-related decisions to maximize the reach of plant-based alternatives.

\section{ACKNOWLEDGMENTS}

The authors acknowledge partial funding from the University Translational Research Network at Iowa State University. 


\section{REFERENCES}

1. Van Loo EJ, Caputo V, Lusk LL. Consumer preferences for farm-raised meat, lab-grown meat, and plant-based meat alternatives: does information or brand matter? Food Policy. 2020;95:101931.

2. Lea EJ, Crawford D, Worsley A. Consumers' readiness to eat a plantbased diet. Eur J Clin Nutr. 2006;60: 342-351.

3. Bryant C, Szejda K, Parekh N, Deshpande V, Tse B. A survey of consumer perceptions of plant-based and clean meat in the USA, India, and China. Front Sustain Food Syst. 2019; 3:11.

4. Good Food Institute. Plant-U.S. retail market data for the plant-based industry. https://www.gfi.org/marketresearch. Accessed July 18, 2020.

5. US Department of Health and Human Services, US Department of Agriculture. 2015-2020 Dietary Guidelines for Americans. 8th ed. US Department of Health and Human Services, US Department of Agriculture; 2015.

6. Bouvard V, Loomis D, Guyton KZ, et al. International Agency for Research on Cancer Monograph Working Group. Carcinogenicity of consumption of red and processed meat. Lancet Oncol. 2015; 16:1599-1600.

7. Willett W, Rockström J, Loken B, et al. Food in the Anthropocene: the EATLancet Commission on healthy diets from sustainable food systems. Lancet. 2019;393:447-492.

8. Heller M, Keoleian G. Beyond Meat's Beyond Burger Life Cycle Assessment: A Detailed Comparison Between a PlantBased and an Animal-Based Protein Source. CSS Report. University of Michigan; 2018.

9. Miki AJ, Livingston KA, Karlsen MC, Folta SC, McKeown NM. Using evidence mapping to examine motivations for following plant-based diets. Curr Dev Nutr. 2020;4:nzaa013.

10. Sanchez-Sabate R, Sabaté J. Consumer attitudes towards environmental concerns of meat consumption: a systematic review. Int $J$ Environ Res Public Health. 2019;16:1220.

11. Sapp SG, Arnot C, Fallon J, et al. Consumer trust in the US food system: an examination of the recreancy theorem. Rural Sociol. 2009;74:525-545.
12. Drewnowski A. Taste preferences and food intake. Annu Rev Nutr. 1997;17: 237-253.

13. Arnett JJ, Žukauskienė R, Sugimura K. The new life stage of emerging adulthood at ages 18-29 years: implications for mental health. Lancet Psychiatry. 2014;1:569-576.

14. Winpenny EM, van Sluijs EM, White M, Klepp KI, Wold B, Lien N. Changes in diet through adolescence and early adulthood: longitudinal trajectories and association with key life transitions. Int J Behav Nutr Phys Act. 2018;15:86.

15. Olfert MD, Barr ML, Mathews AE, et al. Life of a vegetarian college student: health, lifestyle, and environmental perceptions. J Am Coll Health. 2020:1-8.

16. Segovia-Siapco G, Burkholder-Cooley N, Tabrizi S, Sabate J. Beyond meat: a comparison of the dietary intakes of vegetarian and non-vegetarian adolescents. Front Nutr. 2019;13:86.

17. Bradbury K, Tong T, Key T. Dietary intake of high-protein foods and other major foods in Meat-Eaters, poultryeaters, fish-eaters, vegetarians, and vegans in UK Biobank. Nutrients. 2017;9:1317.

18. Freed A, Wong D. The relationship between university students' environmental identity, decision-making process, and behavior. J Sustain Educ. 2019:20.

19. Stern PC, Dietz T, Abel T, Guagnano GA, Kalof L. A value-belief-norm theory of support for social movements: the case of environmentalism. Hum Ecol Rev. 1999;6:81-97.

20. Dietz T, Fitzgerald A, Shwom R. Environmental values. Annu Rev Environ Resour. 2005;30:335-372.

21. Hess DJ, Maki A. Climate change belief, sustainability education, and political values: assessing the need for higher-education curriculum reform. $J$ Clean Prod. 2019;228:1157-1166.

22. Erinosho TO, Pinard CA, Nebeling LC, et al. Development and implementation of the National Cancer Institute's Food Attitudes and Behaviors Survey to assess correlates of fruit and vegetable intake in adults. PLoS One. 2015;10: e0115017.

23. Winham DM, Davitt ED, Heer MM, Shelley MC. Pulse knowledge, attitudes, practices, and cooking experience of Midwestern US university students. Nutrients. 2020;12:3499.

24. Leiner DJ. Too fast, too straight, too weird: non-reactive indicators for meaningless data in internet surveys. Surv Res Methods. 2019;13:229-248.

25. American College Health Association. National College Health Assessment. American College Health Association; 2015.https://www.acha.org/documents/ncha/ACHA-NCHAII_sample. pdf. Accessed March 26, 2021.

26. Dunlap RE, Van Liere KD, Mertig AG, Jones RE. New trends in measuring environmental attitudes: measuring endorsement of the new ecological paradigm: a revised NEP scale. J Soc Issues. 2000;56:425-442.

27. International Food Information Council Foundation (IFIC). A consumer survey on plant alternatives to animal meat. 2020. https://foodinsight.org/ consumer-survey-plant-alternatives-tomeat/. Accessed May 13, 2020.

28. International Food Information Council Foundation (IFIC). 2019 food and health survey. https://foodinsight.org/ 2019-food-and-health-survey/. Accessed April 7, 2021.

29. International Food Information Council Foundation (IFIC). 2018 food and health survey. https://foodinsight.org/ 2018-food-and-health-survey/. Accessed April 6, 2020.

30. Iowa State University. Spring semester 2021 enrollment. https://www.registrar. iastate.edu/sites/default/files/uploads/ stats/S21\%20Enrollment\%20Stats/ LRSPC\%20-\%20S21.pdf. Accessed September 17, 2020.

31. Slade P. If you build it, will they eat it? Consumer preferences for plant-based and cultured meat burgers. Appetite. 2018;125:428-437.

32. Janssen M, Busch C, Rodiger M, Hamm U. Motives of consumers following a vegan diet and their attitudes towards animal agriculture. Appetite. 2016;105:643-651.

33. US Department of Agriculture's National Agricultural Statistics Service. Livestock Press Releases. 2020. https:// www.nass.usda.gov/Statistics_by_ State/Iowa/Publications/Livestock_Report/index.php. Accessed August 5, 2020. 
34. Palmer SM, Winham DM, Oberhauser AM, Litchfield RE. Socio-ecological barriers to dry grain pulse consumption among low-income women: a mixed methods approach. Nutrients. 2018;10:1108.
35. Malek L, Umberger WJ, Goddard E. Committed vs. uncommitted meat eaters: understanding willingness to change protein consumption. Appetite. 2019;138:115-126.
36. Schwarz M, Bonhotal J. Carbon footprint of a university compost facility: case study of Cornell Farm Services. Compost Sci Util. 2018;26: 128-143.

SNEB 2021 Annual Conference: Raising Reliance and Resilience Rapid Reviews with JNEB Editors

Associate Editors will be available to provide feedback to potential authors or reviewers. Rapid reviews can cover almost any topic on the publishing process, including:

- Journal scope and paper suitability

- Experimental design and statistics

- General manuscript preparation before submission

- The peer-review process

Tuesday, August 10 | 2:15-3:35 pm (EDT)

Sign up for a 20-minute appointment at https://www.signupgenius.com/go/20F0A4FADA62DABFE3-sneb7 